\title{
Serotonin Activation of a Cyclic AMP-Dependent Sodium Current in an Identified Neuron from Helisoma trivolvis
}

\author{
Christopher J. Price and Jeffrey I. Goldberg \\ Department of Zoology, University of Alberta, Edmonton, Alberta, Canada T6G 2E9
}

The mechanisms by which neurotransmitters regulate neurite extension and growth cone motility have been extensively studied using identified Helisoma neurons regenerating in cell culture. Specific neurons, such as buccal neuron $\mathrm{B19}$, display a complex response to the addition of 5-HT involving the generation of action potentials, influx of extracellular calcium, and cessation of neurite extension and growth cone motility. While several studies have addressed the role of calcium in this cascade, little is known about the mechanism underlying the 5-HT-induced excitation of neuron $\mathrm{B19}$. Therefore, we have begun to characterize the ion currents, receptors, and second messengers involved in the 5-HT-dependent depolarization of B19. Exposure of B19 to 5-HT resulted in the activation of a maintained inward current. Ion substitution experiments revealed that this current was carried mainly by sodium ions. The use of 8-bromoCAMP, forskolin, or the phosphodiesterase inhibitor isobutyl methylxanthine (IBMX) to increase intracellular CAMP levels all resulted in inward current activation in the absence of 5-HT. Moreover, preloading the neuron with 8-bromo-cAMP was sufficient to prevent further current activation by $5-\mathrm{HT}$. In addition, the IBMX-activated current was greatly enhanced when induced in the presence of 5-HT. Protein kinase inhibitors failed to prevent 5-HT activation of sodium current, suggesting that CAMP may directly activate the current, independent of phosphorylation. Pharmacological experiments showed the $\mathrm{B} 19 \mathrm{5}-\mathrm{HT}$ receptor has an $\mathrm{EC}_{50}$ of approximately $10^{-7} \mathrm{M}$ and can be activated by various indole analogs of 5-HT. Furthermore, methysergide displayed partial agonist activity. These results have identified receptors and ion currents that may play crucial roles in the regulation of nervous system development during embryogenesis in Helisoma.

[Key words: molluscan electrophysiology, ion channel, 5-HT pharmacology, second messengers, neuronal regeneration, neuronal development]

\footnotetext{
Received Dec. 1, 1992; revised Apr. 20, 1993; accepted May 27, 1993.

We thank Dr. J. P. Chang for helpful discussions and for gifts of $\mathrm{H} 7$ and $\mathrm{H} 89$ and $K$. Price for reading the manuscript. This work was supported by a Natural Sciences and Engineering Research Council of Canada grant to J.I.G. (UO553), and a Natural Sciences and Engineering Research Council of Canada postgraduate scholarship to C.J.P.

Correspondence should be addressed to Christopher J. Price, Department of Zoology, University of Alberta, CW312 Biological Sciences Center, Edmonton, Alberta, Canada T6G 2E9.

Copyright (C) 1993 Society for Neuroscience $0270-6474 / 93 / 134979-09 \$ 05.00 / 0$
}

A considerable amount of recent evidence has accumulated supporting the hypothesis that neurotransmitters function as regulatory factors during nervous system development (Lankford et al., 1987; Mattson et al., 1988a; Budnik et al., 1989; Goldberg and Kater, 1989; Sikich et al., 1990). The in vitro regeneration of identified neurons from the snail Helisoma trivolvis has provided a useful model to explore in detail one possible mechanism through which neurotransmitters act as developmental regulatory factors. When specific identified neurons were placed in cell culture and exposed to 5-HT, growth cone motility and neurite extension were reversibly inhibited (Haydon et al., 1984; 1987). To determine if endogenous 5 -HT could act as a regulator of neurite development during embryogenesis, Goldberg and Kater (1989) used 5,7-dihydroxytryptamine to deplete 5-HT concentrations transiently in Helisoma embryos. This treatment resulted in aberrations in neuronal morphology, incidences of abnormal dye coupling, and enhanced synaptic efficacy in the same identified neurons as those affected by 5 -HT in the cell culture experiments on adult neurons.

Studies examining the intracellular mechanism through which 5-HT exerts its actions on growth cone motility and neurite extension have provided considerable insight into how growth cones interpret the regulatory signals they encounter (Kater and Mills, 1991). 5-HT was found to depolarize the responsive neuron B19, a necessary step for the inhibition of neurite outgrowth (McCobb and Kater, 1988). Fura-2 mcasurcments and cxpcrimental manipulation of growth cone calcium levels further revealed that the influx of calcium through voltage-gated calcium channels was also a necessary intermediary in the inhibition of neurite extension and growth cone motility in B19 (Cohan et al., 1987; Mattson and Kater, 1987). Recent evidence suggests that calcium ultimately affects the processes associated with neurite extension via binding to calmodulin, since a specific calmodulin antagonist, CGS 9343B, can inhibit 5-HT-induced cessation of neurite extension (Polak et al., 1991). While the majority of studies have concentrated on the role that calcium plays in this process, little is known about the initial events that underlie the 5-HT-induced depolarization. Such information would be beneficial since it would identify receptors and ion channels with potentially important roles in nervous system development that would therefore be substrates for developmental regulation. Furthermore, it could help to define the role of second messengers, such as cAMP, which has been shown to mimic the effects of 5-HT on neurite outgrowth (Mattson et al., 1988b). Therefore, we have undertaken a study, using the tightseal whole-cell recording configuration, to characterize the ion channels, second messengers, and receptors that mediate 5-HTinduced depolarization of the identified neuron B19. 
Figure 1. 5-HT depolarizes neuron B19 through activation of an inward current. $A$, Current-clamp recording $\left(V_{m},-60 \mathrm{mV}\right)$ showing that bath application of 5-HT to a cultured B19 (25 $\mu \mathrm{M}$ final concentration) resulted in maintained depolarization and spiking. $B$, The delivery of hyperpolarizing current pulses of amplitudes 100,200 , and $300 \mathrm{pA}$ pre- and postapplication of 5-HT revealed that accompanying depolarization was a decrease in cell input resistance. As measured from the 100 pA pulse, this represented an average decrease in input resistance of $21 \pm$ $2.98 \%(n=6)$. Both the pre- and postapplication recordings were performed with the membrane potential hyperpolarized to $-90 \mathrm{mV}$. $C$, In voltage clamp, rapid bath exchange for saline containing $25 \mu \mathrm{M}$ 5-HT resulted in the activation of an inward current. Activation was reversible upon washing with 5-HT-free saline. $V_{\text {holding }}=-70 \mathrm{mV}$; bar indicates duration of 5-HT exposure.

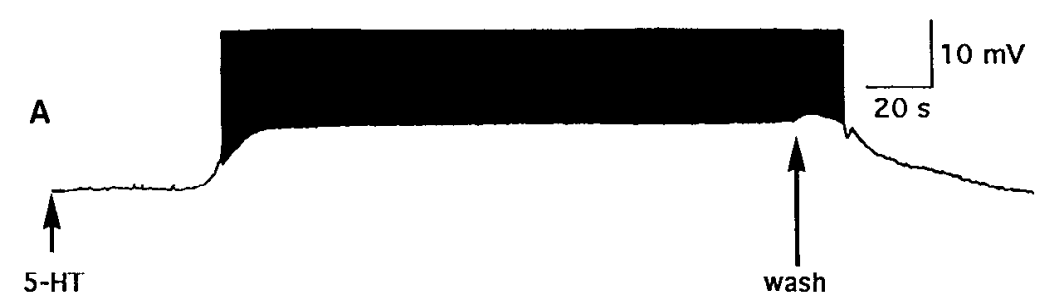

B

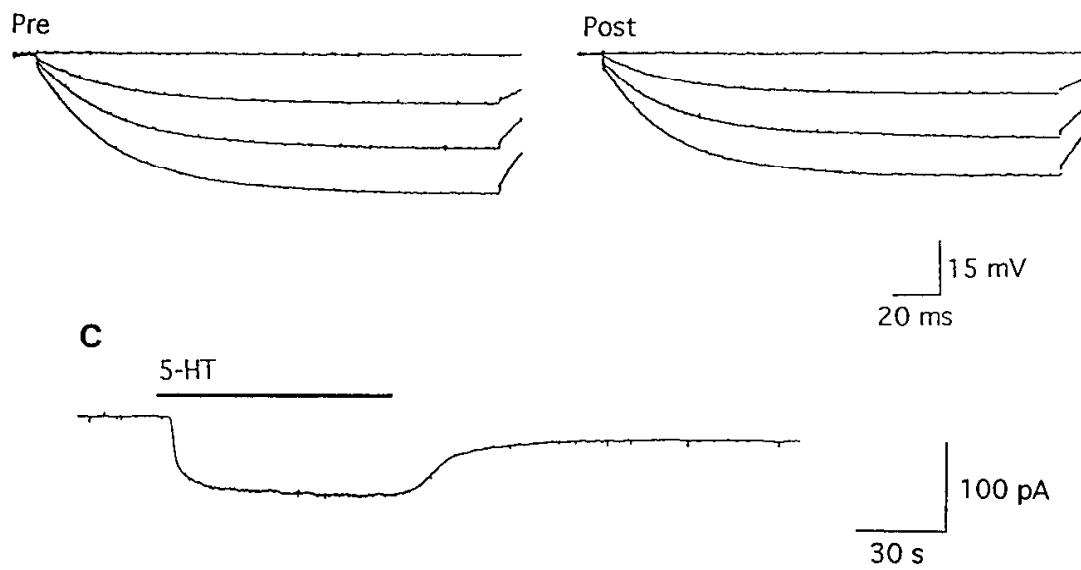

The data presented here show that $5-\mathrm{HT}$ results in the activation of a cAMP-dependent sodium current, which leads to membrane depolarization. Moreover, current activation does not appear to involve protein kinase activity. Finally, we have begun to describe pharmacologically the receptors mediating the action of 5-HT on B19.

\section{Materials and Methods}

Animals. Snails used as neuron donors were members of an inbred laboratory colony of albino Helisoma trivolvis. They were raised in flowthrough aquaria under a $12 \mathrm{hr}$ light $/ 12 \mathrm{hr}$ dark photoperiod and fed a diet of trout chow (Vextra) and lettuce.

Cell culture. The method used for isolation of identified neurons from IIelisoma buccal ganglia follows closely that used by Haydon et al. (1985). Snails of between 8 and $15 \mathrm{~mm}$ vertical shell diameter were deshelled and placed in a $25 \%$ Listerine/artificial pond water solution (0.025\% Instant Ocean) for $15 \mathrm{~min}$. This served to partially sterilize and anesthetize the snails for subsequent dissection. Under aseptic conditions, buccal ganglia were removed from the snails and then placed in $0.2 \%$ trypsin for $15 \mathrm{~min}$ prior to isolation of neurons. Following trypsinization, ganglia were pinned onto a silicone rubber (General Electric) pad, and the interganglionic commissure and lateral nerve trunks were crushed. Using an electrolytically sharpened tungsten needle, the ganglionic sheath was slit adjacent to neuron B 19 and the neuron's cell body was gently pushed out through the slit. The B19 cell body was then withdrawn with suction into the opening of a micropipette that was attached to a micrometer syringe (Canlab). Using gentle repeated cycles of negative and positive pressure, the neuron's axons were gradually stretched until they broke, thereby freeing the neuron.

Isolated neuron $\mathrm{B} 19 \mathrm{~s}$ were placed either onto coverglass pieces or 35 mm culture dishes (Falcon 3001), both of which were polylysine coated and conditioned with Helisoma neurite outgrowth-promoting factors (Wong et al., 1981). Culture dishes were conditioned by incubating 2 $\mathrm{ml}$ of Helisoma defined medium (50\% Liebowitz; GIBCO special order, containing no added salts and supplemented with $40 \mathrm{~mm} \mathrm{NaCl}, 1.7 \mathrm{~mm}$ $\mathrm{KCl}, 4.1 \mathrm{mM} \mathrm{CaCl}_{2}, 1.5 \mathrm{~mm} \mathrm{MgCl}, 5 \mathrm{mM} \mathrm{HEPES}, 50 \mathrm{mg} / \mathrm{ml}$ gentamicin, and $0.015 \%$ glutamine; $\mathrm{pH} 7.3-7.4$ ) with the central ganglionic rings from four snails. The incubation was carried out for $2-4 \mathrm{~d}$ at room temperature. To condition coverglass, pieces were placed on the bottom of $35 \mathrm{~mm}$ culture dishes and the above procedure was then employed. The ganglionic rings were removed from the culture dishes prior to neuron plating.

Electrophysiological recording. Whole-cell recordings were performed at room temperature either in a recording chamber (Warner Instruments) that allowed for rapid, gravity-fed exchange of the bathing solution or, alternatively, directly in the culture dish. In the latter situation, drug application was performed by addition of a concentrated volume $(10 \mu \mathrm{l})$ to the bath to yield the final concentration. Cells used for recordings were plated on the day before use. Cells that possessed either neuritic processes or a skirt of lamellapodium but had yet to extend processes were used in recordings. Qualitatively, both types of cells gave the same response to serotonin and the other experimental agents.

The basic extracellular recording solution consisted of a saline solution composed of $51.3 \mathrm{mM} \mathrm{NaCl}, 1.7 \mathrm{mM} \mathrm{KCl}, 4.1 \mathrm{mM} \mathrm{CaCl}_{2}, 1.5 \mathrm{~mm}$ $\mathrm{MgCl}_{2}$, and $5 \mathrm{~mm}$ HEPES; $\mathrm{pH}$ 7.3-7.4. For sodium-free recording situations, sodium was substituted with Tris. 5-HT and the various pharmacological agents were made up fresh daily. $\alpha$-Methyl 5-HT $(\alpha \mathrm{m}$ 5-HT), 5-carboxyamidotryptamine (5-CT), and methysergide were obtained from Research Biochemicals Inc., while all other chemicals were obtained from Sigma.

Electrodes for whole-cell recordings were fashioned from either lead glass (World Precision Instruments PG61165-4; $1.65 \mathrm{~mm}$ o.d.) or from borosilicate glass (World Precision Instruments 1B150F; $1.5 \mathrm{~mm}$ o.d.) Electrodes were pulled on either a Narishigi PB-7 vertical puller or a Flaming Brown horizontal puller (Sutter Instruments). Whole-cell electrodes, when filled with the standard recording solution $(54.4 \mathrm{mM} \mathrm{K}$-aspartate, 2 mM EGTA, 2 mM $\mathrm{MgCl}_{2}$, 5 mM HEPES, $5 \mathrm{~mm}$ dextrose, 5 mM ATP, and $1 \mathrm{~mm}$ GTP; pH 7.3-7.4), had resistances of 1-5 M $\Omega$. Electrodes typically were coated near their tips with dental wax to lower noise levels. All electrodes were heat polished.

Recordings were made using a Dagan 3900 integrating patch-clamp amplifier, following standard whole-cell recording procedures (Hamill et al., 1981). Recordings were filtered at $2 \mathrm{kHz}$, using the 4-pole Bessel filter internal to the Dagan 3900. Generally, series resistance compensation was not employed during recordings, since the nature of the responses measured here did not warrant its use. Whole-cell responses were output either to a Gould RS3200 chart recorder or to a 80386 IBM clone equipped with the INDEC FASTLAB suite of data acquisition and analysis programs. 


\section{Results}

5-HT-dependent depolarization of neuron $B 19$

Previous experiments examining 5-HT-dependent excitation of B19 used extracellular patch recordings to assay this response (McCobb and Kater, 1988). Here we show the responses to 5-HT recorded in the whole-cell recording configuration. While more invasive, it allowed for the measurement of changes in input resistance as well as the introduction of factors to the interior of the cell.

In the current-clamp recording mode, exposure of neuron B19 to $25 \mu \mathrm{M} 5$-HT resulted in robust membrane depolarization and the initiation of spiking activity (Fig. $1 A$ ). This persisted for as long as $5-\mathrm{HT}$ was present in the bath; in one instance the cell remained depolarized for over $4 \mathrm{hr}$. Depolarization was reversible upon washing. Associated with depolarization, generally, was an overall decrease in cell input resistance, as determined by the decrease in the amplitude of voltage responses to hyperpolarizing current pulses (Fig. $1 B$ ).

In voltage-clamp recordings, the response to 5 -HT exposure was manifested as the activation of an inwardly directed, maintained current. This was consistently associated with an overall increase in the baseline noise level, indicative of an increase in ion channel activity (Fig. $1 C$ ). From a sample of 14 cells, the current induced by $25 \mu \mathrm{M} 5-\mathrm{HT}$ and recorded at a holding potential of $-70 \mathrm{mV}$ had a mean amplitude of $152 \pm 19 \mathrm{pA}$ and ranged from 67 to $267 \mathrm{pA}$.

Current-voltage $(I / V)$ relationships were obtained for the B19 5-HT-activated inward current using a staircase protocol. The holding potential was increased by $10 \mathrm{mV}$ increments every 1 sec from $-100 \mathrm{mV}$ to $-10 \mathrm{mV}$ before and after application of 5-HT. The voltage range used was chosen to minimize contamination by voltage-gated currents. The steady-state current level at the end of each $1 \mathrm{sec}$ interval was then measured and used to calculate the current due to 5-HT exposure. Subtraction of the current values obtained before 5-HT application from those obtained during 5-HT exposure revealed the 5-HT-induced current. 5-HT-activated current remained inward over the range of hyperpolarized potentials and approached zero current near $-10 \mathrm{mV}$ (Fig. $2 A ; n=7$ ). This suggests that the channel activated by $5-\mathrm{HT}$ is not totally selective for sodium ions.

A curious increase in inward current level was seen in the 5-HT $I / V$ curve between -40 and $-30 \mathrm{mV}$. A negative slope conductance was also seen in a similar voltage range in the steady-state $I / V$ curve for B19 prior to 5-HT application (Fig. $2 B$ ). This could represent an underlying voltage dependence for the ion channel activated by $5-\mathrm{HT}$. Alternatively, it could represent a separate conductance that is enhanced by 5 -HT. Interestingly, Taussig et al. (1989) saw a similar situation in the Aplysia neuron B15, where the 5-HT $I / V$ curve also possessed an increased inward current level between -30 and $-15 \mathrm{mV}$.

To examine the ionic species carrying the 5-HT-activated inward current over the hyperpolarized range of potentials, ion substitution experiments were performed. In experiments where potassium aspartate in the electrode solution was substituted with $N$-methylglucamine, 5 -HT still induced the activation of inward current (data not shown; $n=8$ ). However, replacement of external sodium with Tris resulted in a marked decrease in the amplitude of inward current, a shift in the reversal potential to more negative potentials, and elimination of the region of negative slope conductance (Fig. $2 A ; n-7$ ). Therefore, sodium appears to be the major ion species carrying 5-HT-activated
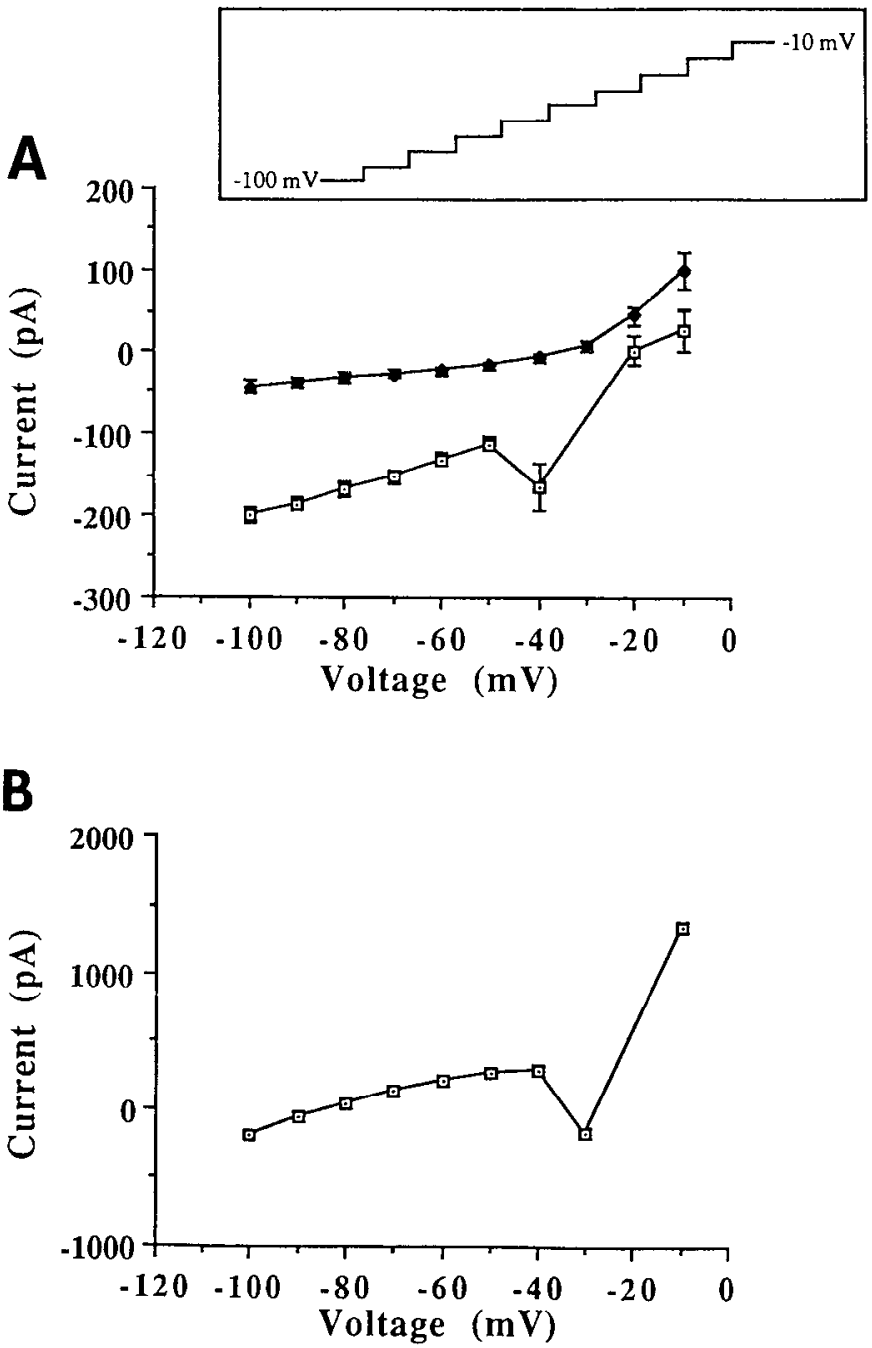

Figure 2. $I / V$ curves for 5-HT-dependent inward current. A, Subtraction of the steady-state current measured before application of 25 $\mu \mathrm{M}$ 5-HT from that measured after application. Shown are the mean currents obtained under normal sodium conditions (open symbols) and under sodium-free conditions (solid symbols), demonstrating the sodium dependence of the current. Inset shows the staircase protocol used, with each voltage step being $1 \mathrm{sec}$ in duration. Current was measured at the end of each step. Error bars represent SEM ( $n=7$ for both open and solid symbols). $B$, Representative $I / V$ curve for steady-state current in $\mathrm{B} 19$ in the absence of 5-HT using the staircase protocol described in $A$. Note the negative slope region of the $I / V$ curve between -40 and $-30 \mathrm{mV}$.

inward current. Positive to the reversal potential, the steep slope of the outward current suggests the 5-HT-activated current is outwardly rectifying.

\section{Role of cAMP in 5-HT-dependent sodium current activation}

Previous experiments had implicated cAMP as a second messcnger mediating the actions of 5-HT on growth cone motility and neurite elongation of neuron B19 (Mattson et al., 1988b). To determine if 5-HT-dependent sodium current activation involved a cAMP-dependent mechanism, the actions of cAMP analogs and agents influencing the metabolism of cAMP were investigated.

Exposure of neuron B19 to $2 \mathrm{mM} 8$-bromo-cAMP resulted in the activation of inward current (Fig. $3 A ; n-8$ ). However, further addition of $25 \mu \mathrm{M} 5-\mathrm{HT}$ still produced substantial inward 
A

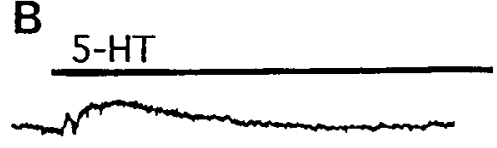

C

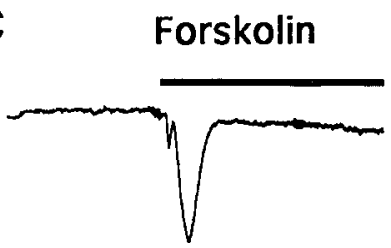

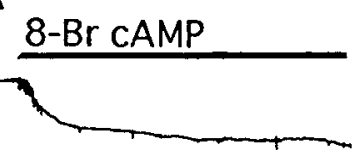

A $100 \mathrm{pA}$

\section{$30 \mathrm{~s}$}

Figure 3. Activation of inward current by cAMP. $A$, Bath exchange for saline containing $2 \mathrm{~mm} 8$-bromo-cAMP resulted in inward current activation. $B$, Preloading of the B19 cell body with $100 \mu \mathrm{M} 8$-bromocAMP prevented the activation of inward current normally seen following bath exchange for 5-HT-containing saline. The small, transient outward current, a perfusion artifact associated with the bath exchange system, was not consistently observed. $C$, Bath exchange for saline containing $32 \mu \mathrm{M}$ forskolin resulted in transient activation of an inward current. In all instances, the holding potential was $-70 \mathrm{mV}$. Bars indicate duration of 8-bromo-cAMP, 5-HT, and forskolin exposure.

current (data not shown). To determine if this additivity was a reflection of inward current activation not involving cAMP as a second messenger or was due to inadequate membrane permeability of the cAMP analog, a pipette solution containing 100 $\mu \mathrm{M}$ 8-bromo-cAMP was used to load the neurons effectively with the analog. Under these conditions, bath exchange for 5-HTcontaining saline failed to result in gating of 5-HT-dependent sodium current (Fig. $3 B ; n=6$ ), thereby supporting the involvement of cAMP in the activation process.

To test further the hypothesis that cAMP mediates the activation of the 5-HT-dependent sodium current, agents that stimulate the formation or prevent the degradation of cAMP were also examined. Application of $32 \mu \mathrm{M}$ forskolin, a stimulator of adenylate cyclase, induced a transient inward current (Fig. 3C; $n=3$ ). The transient nature of the current was likely due to insufficient long-term stimulation of cyclase activity over endogenous phosphodiesterase activity with the concentration of forskolin used.

If 5-HT-activated sodium current involves a cAMP-dependent step, then the phosphodiesterase inhibitor isobutyl methylxanthine (IBMX) should potentiate this response. Exposure of $\mathrm{B} 19$ to $0.5 \mathrm{mM}$ IBMX resulted in the weak activation of inward current (Fig. $4 A ; n=6$ ). The same cells were then sub-

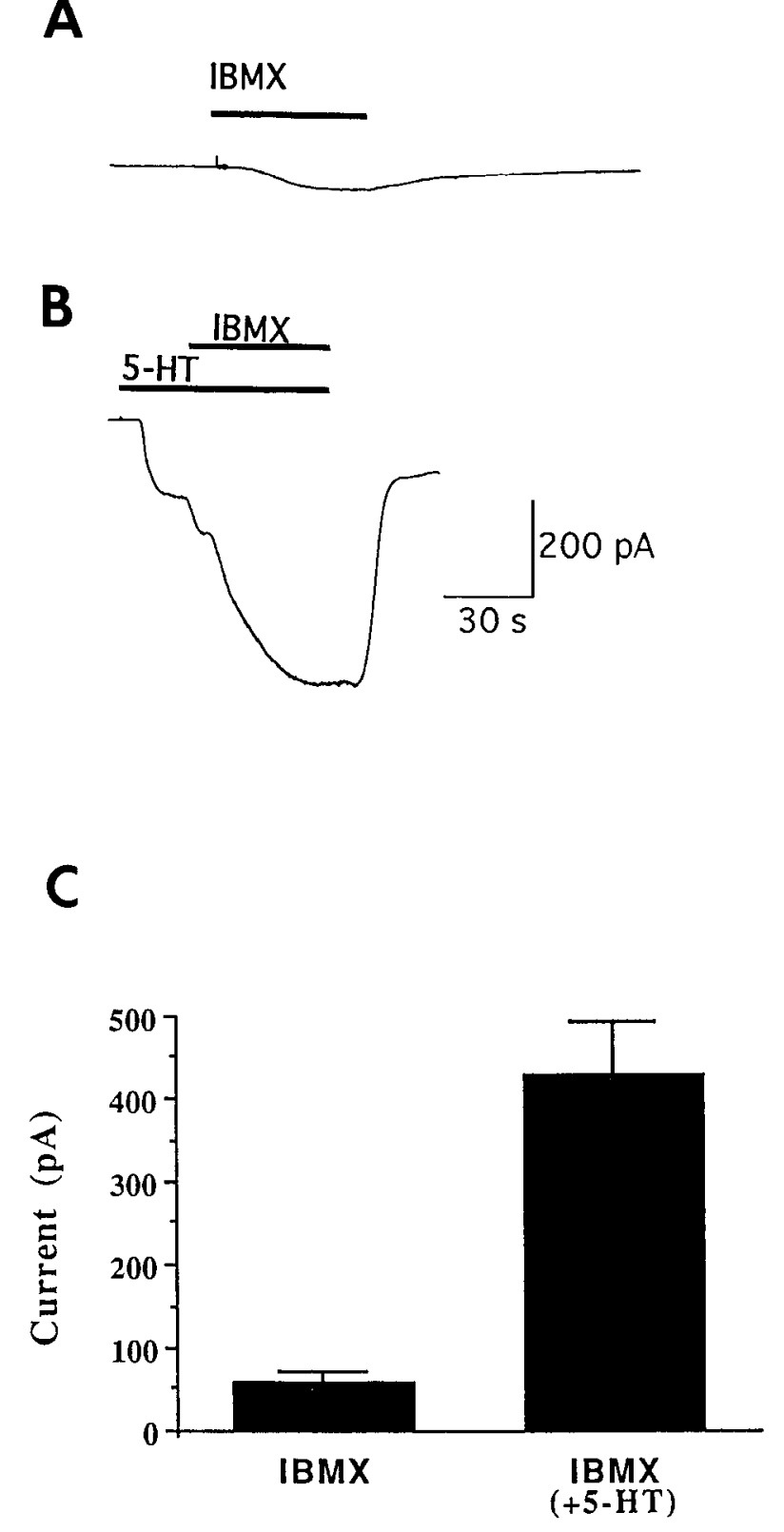

B

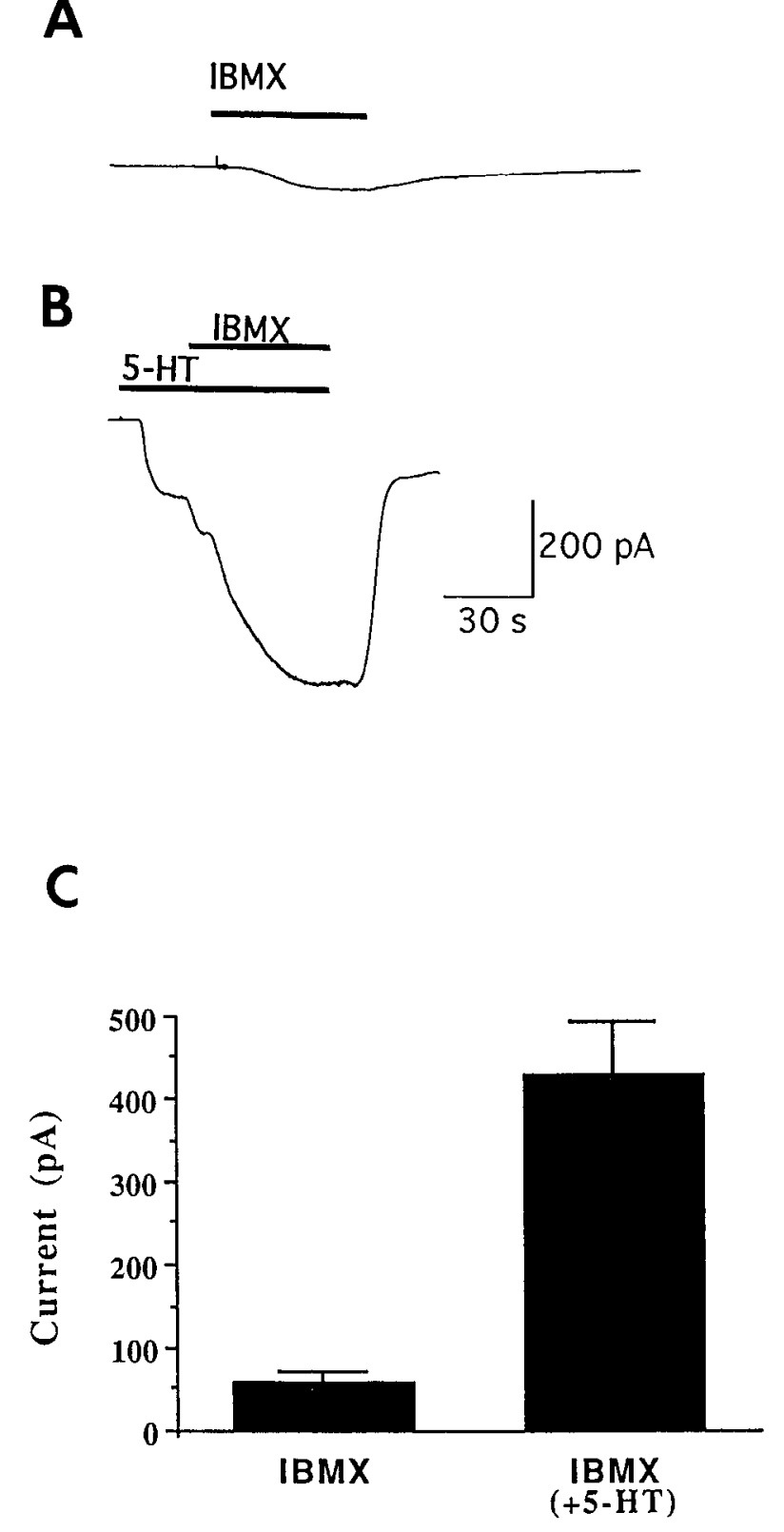

C

Figure 4. Exposure of B19 to the membrane permeable phosphodiesterase inhibitor IBMX resulted in inward current activation. A, Bath exchange for saline containing $0.5 \mathrm{~mm}$ IBMX resulted in weak inward current activation. $B$, In the same cell as in $A$, following washing, bath exchange for $25 \mu \mathrm{M} 5$-HT-containing saline-induced inward current activation as expected. Application of $0.5 \mathrm{~mm}$ IBMX in the presence of 5-HT resulted in stronger activation of inward current than seen with IBMX alone. In all instances, the holding potential was $-70 \mathrm{mV}$. Bars indicate duration of IBMX and 5-HT exposure. $C$, Graph quantifying the mean inward current due to $0.5 \mathrm{mM}$ IBMX alone and the current due to $0.5 \mathrm{~mm} \mathrm{IBMX}$ following initial $5-\mathrm{HT}$ exposure. This latter value was measured from the peak of the 5-HT response and does not include the current activated by 5-HT. Error bars represent SEM $(n=6)$.

jected to a protocol in which the IBMX was washed out, followed by application of $25 \mu \mathrm{M} 5-\mathrm{HT}$ and then reapplication of $0.5 \mathrm{mM}$ IBMX. In the presence of 5-HT, a larger-amplitude IBMXstimulated current was always observed (Fig. $4 B$ ). Owing to the much larger current seen in response to IBMX following initial stimulation of the cell with $5-\mathrm{HT}$, this suggests $5-\mathrm{HT}$ activates cyclase activity in $\mathrm{B} 19$ (Fig. $4 C$ ). 


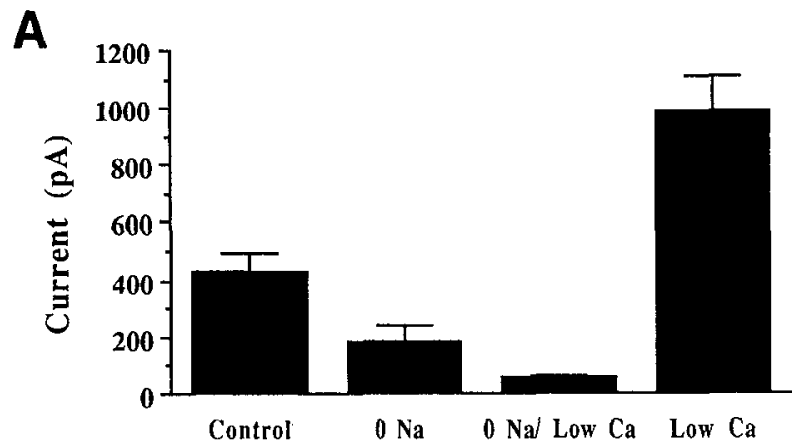

B

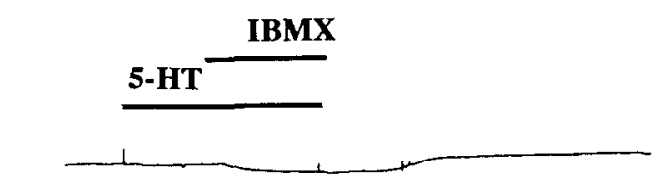

$0 \mathrm{Na}$

$100 \mu \mathrm{M} \mathrm{Ca}$

C

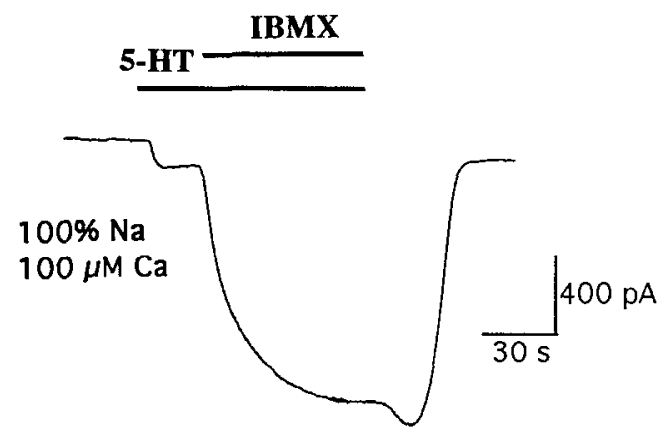

Figure 5. Sodium and calcium dependency of IBMX-potentiated inward current. $A$, Graph summarizing the results of ion substitutions on the amplitude of IBMX-potentiated inward current. Control represents mean IBMX-potentiated current under normal ionic conditions as measured in Figure 4, $B$ and $C$. Error bars represent SEM $(n=6,5,6$, and 6 , respectively). $B$, Under $0 \mathrm{Na}^{+}, 100 \mu \mathrm{M} \mathrm{Ca}{ }^{2+}$ conditions, very little IBMX-potentiated inward current was seen. $C$, Same cell as $B$. Following washing and excharging the recording solution for $100 \% \mathrm{Na}^{+}$, and 100 $\mu \mathrm{M} \mathrm{Ca}^{2+}$ saline, a very large IBMX-potentiated current was seen. Bars indicate the duration of 5-HT and IBMX exposure; holding potential was $-70 \mathrm{mV}$.

To determine if the IBMX-potentiated current was carried by sodium, ion substitution experiments were again performed. In the absence of sodium, $0.5 \mathrm{mM}$ IBMX still resulted in significant inward current following initial 5-HT application (Fig. $5 A ; n=5$ ). The current-voltage relationships seen for this IBMX current did not indicate it was due to the reduction of a potassium current, since the current was inward at very negative potentials (data not shown) and the equilibrium potential for potassium ions was approximately $-90 \mathrm{mV}$ under these conditions. Therefore, the possibility that calcium ions were carrying this current was examined by decreasing extracellular calcium from $4.1 \mathrm{~mm}$ to $100 \mu \mathrm{M}$. Under low calcium and zero sodium conditions, very little current was seen in response to 5-HT and subsequent IBMX application (Fig. $5 B ; n=6$ ). Sur-

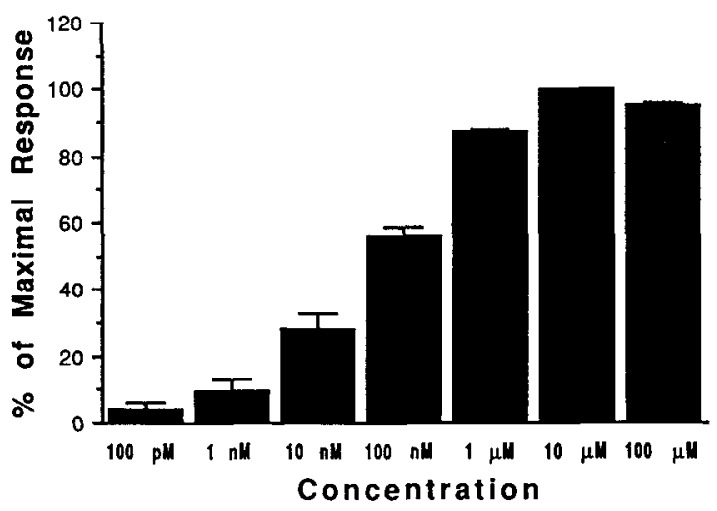

Figure 6. Dose-response relationship for 5-HT-activated sodium current: graph showing the contribution of different concentrations of 5-HT to inward current activation, obtained from concentration step experiments where neurons wcre cxposed to increasing concentrations of 5-HT without intermediating washes. For all cells, the maximal response was observed at a concentration of $10 \mu \mathrm{M}$. In all instances the holding potential was $-70 \mathrm{mV}$. Error bars represent the SEM.

prisingly, upon washing and replacement of the bath solution with low-calcium, normal-sodium saline, a very large IBMXpotentiated current was observed (Fig. $5 C$ ). Taken together, these results suggest the following. (1) Sodium is the main carrier of the IBMX-potentiated current. (2) Under sodium-free conditions, it is apparent that calcium ions can permeate the channel. (3) Because the amplitude of the IBMX-potentiated current was much larger under low-calcium conditions than under normal-calcium conditions, this suggests that calcium ions might also have an inhibitory influence on channel conductance (Fig. 5A).

The above results support a role for CAMP in the activation of 5-HT-dependent sodium current. To determine if this action involved the activity of protein kinases, the effects of protein kinase inhibitors were assayed. Kinase inhibitors were dissolved directly into the electrode solution, and recordings were made using neurons that had yet to extend neurites. This avoided complications due to poor diffusion of the inhibitor into neurites. The nonspecific kinase inhibitor $\mathrm{H} 7$, at concentrations $(100 \mu \mathrm{M})$ that should inhibit most kinase activity, was ineffective at preventing the activation of the 5-HT-dependent sodium current. In four cells, currents ranging from 60 to $167 \mathrm{pA}$ were seen in response to $25 \mu \mathrm{M} 5-\mathrm{HT}$. Moreover, in an additional four cells, $50 \mu \mathrm{M} \mathrm{H7}$ did not prevent robust depolarization of B19 following exposure to $25 \mu \mathrm{M} 5$-HT. Similarly, the more spccific cAMP-dependent kinase inhibitor H89 $(10 \mu \mathrm{M})$ also did not prevent robust depolarization of $\mathrm{B} 19(n=3)$. Therefore, while cAMP is likely to be involved in the activation of 5-HTdependent sodium current, it does not appear to act through the stimulation of protein kinases.

\section{Pharmacology of the B19 5-HT receptor}

To examine the dose-response relationship for 5-HT-activated sodium current, the sustained nature of the 5-HT response was taken advantage of. When $25 \mu \mathrm{M} 5-\mathrm{HT}$ was repeatedly applied to B19 with intermediating washes, a constant decrease in the amplitude of the 5-HT-activated sodium current was observed. In contrast, with a single application of 5-HT, the activated current maintained a constant amplitude once a steady-state level had been reached. Therefore, B19s were exposed to increasing concentrations of 5-HT without intermediating wash 
A

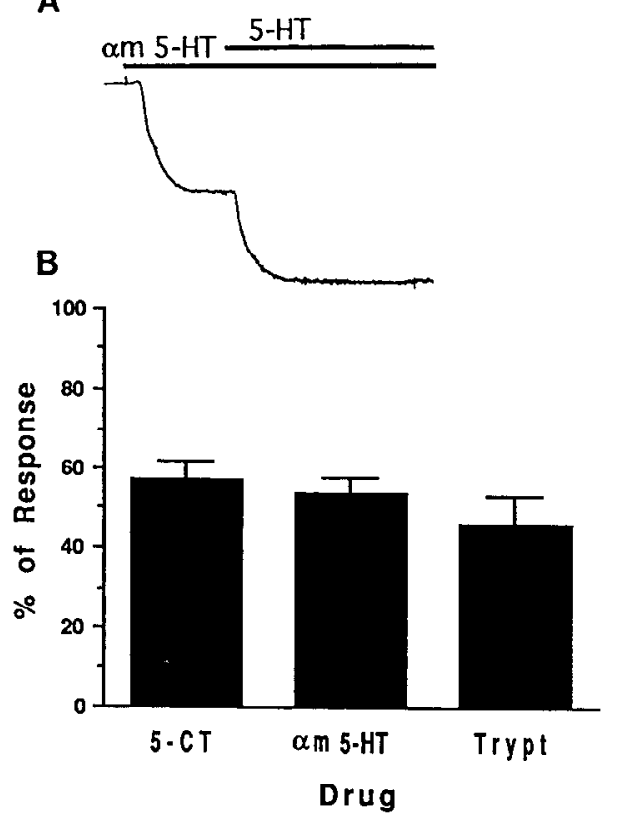

C

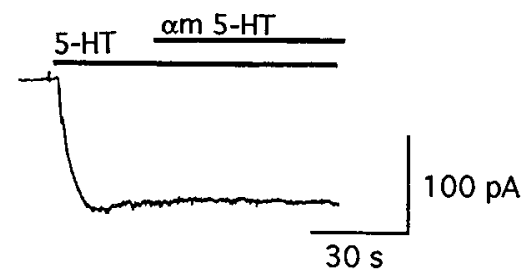

Figure 7. Activities of indole agonists at the B19 5-HT receptor. $A$, Representative trace showing the inward current activated by $100 \mu \mathrm{M}$ $\alpha \mathrm{m}-5$-HT followed by a $25 \mu \mathrm{M} 5-\mathrm{HT} / 100 \mu \mathrm{M} \alpha \mathrm{m}-5-\mathrm{HT}$ mixture. $B$, Graph represents the mean $( \pm$ SEM $)$ inward current activated by the agonist alone as a percentage of the total current response to the agonist plus $25 \mu \mathrm{M}$ 5-HT. See $A$ for prolocol; $170 \mu \mathrm{M}$ 5-CT $(n=6) ; 100 \mu \mathrm{M}$ $\alpha \mathrm{m}-5$-HT $(n=4) ; 100 \mu \mathrm{M}$ tryptamine (Trypt; $n=2)$. $C$, In the same cell as in $A$, when the neuron was exposed first to $5-\mathrm{HT}$ and then to the 5-HT/ $\alpha \mathrm{m}-5-\mathrm{HT}$ mixture, additivity was never seen. This result was observed for all the indole agonists tested. In all instances, the holding potential was $-70 \mathrm{mV}$. Bars represent the duration of $\alpha \mathrm{m}-5-\mathrm{HT}$ and 5-HT exposure.

periods. Thus, dose-response relationships were determined for single cells. This procedure yielded a mean current amplitude at the dose giving maximal current activation $(10 \mu \mathrm{M} ; 138 \pm$ $15 \mathrm{pA}, n=8$ ) that was not significantly different from that seen after a single application of $25 \mu \mathrm{M} 5$-HT (152 $\pm 19 \mathrm{pA}, n=14$; $t$ test, $p=0.6107$ ).

Dose-response experiments revealed that the $\mathrm{EC}_{50}$ for $5-\mathrm{HT}$ activation of sodium current was approximately $100 \mathrm{~nm}$ (Fig. $6 ; n=8$ ). Furthermore, the threshold for current activation was relatively low, with measurable current being seen at 5-HT concentrations as low as $0.1 \mathrm{~nm}$ in some cells.

In order to characterize pharmacologically the receptor that mediates the activation of 5-HT-dependent sodium current, several compounds were analyzed for specific activity at the B19 5-HT receptor. Compounds that displayed apparent antagonist activity on the 5-HT-induced inward current included mianserin $(25 \mu \mathrm{M})$, cyproheptadine $(50 \mu \mathrm{M})$, and $R(+)$-8-hydroxydipropylaminetetralin (8-OH-DPAT $50 \mu \mathrm{M}$; data not shown). However, interpretation of these results was hampered by the finding that all of these compounds had additional nonspecific
A

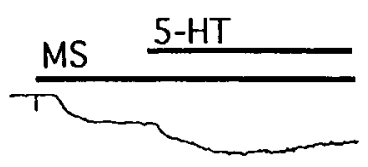

B
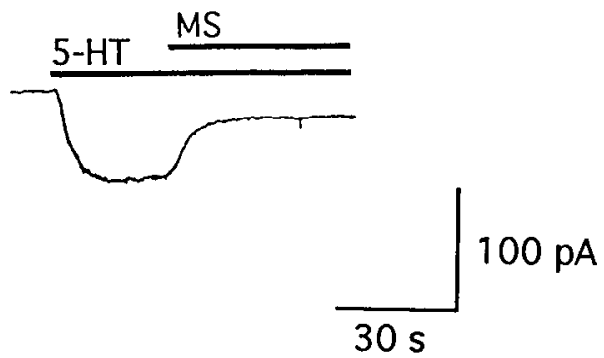

Figure 8. Activity of methysergide (MS) at the B19 5-IIT receptor. $A$, Bath exchange for saline containing $25 \mu \mathrm{M}$ MS resulted in weak activation of inward current. Subsequent exchange for $25 \mu \mathrm{M}$ methysergide/ $25 \mu \mathrm{M}$ 5-HT mixture gave further activation of inward current. $B$, In the same cell as in $A$, after washing, reverse order of drug application revealed apparent antagonistic activity of methysergide. In all instances, the holding potential was $-70 \mathrm{mV}$. Bars represent the duration of methysergide and 5-HT exposure.

effects at the concentrations required for inhibition, namely, the reversible blockage of voltage-gated sodium and potassium currents.

In contrast, a number of drugs were found to have activity as specific agonists or partial agonist/antagonists at this site. Using a protocol in which the drug alone was exposed to B19 and then without a drug-free wash period the bath saline was exchanged for one containing the drug plus $25 \mu_{\mathrm{M}} 5-\mathrm{HT}$, three drugs-5-CT $(n=6), \alpha \mathrm{m}-5-\mathrm{HT}(n=4)$, and tryptamine $(n=$ 2)-acted as agonists at the B19 5-HT receptor. Since each drug contributed only about half of the total drug/5-HT response (Fig. $7 A, B$ ), these compounds appeared to be less effective agonists than 5-HT itself. Furthermore, when the above experiments were performed in the reverse order, with $25 \mu \mathrm{M} 5-\mathrm{HT}$ delivered first followed by the drug/5-HT mixture, additivity was never seen (Fig. $7 C$ ). Therefore, these results confirm that 5-CT, $\alpha \mathrm{m}-5-\mathrm{HT}$, and tryptamine act as weak agonists at the B19 5-HT receptor.

Whereas 5-CT, $\alpha \mathrm{m}-5-\mathrm{HT}$, and tryptamine were shown to possess weak agonist activity at the B19 5-HT receptor, a fourth drug displayed more complex activity at this receptor. Methysergide $(25 \mu \mathbf{M})$, a drug having antagonist activity at vertebrate 5-HT receptors (Peroutka, 1988), was found to have weak agonist activity at the $\mathrm{B} 19$ 5-HT receptor. Methysergide contributed an average of $44.9 \pm 8 \%(n=5)$ to the total current elicited by methysergide and 5-HT (Fig. $8 A$ ). However, when the methysergide/5-HT mixture was delivered following 5-HT exposure, the 5-HT-induced inward current response was reduced by an average of $60 \pm 3.5 \%$ (Fig. $8 B ; n=5$ ). Therefore, methysergide appears to act as a partial agonist/antagonist at the B19 5-HT receptor site.

\section{Discussion}

The neurotransmitter 5-HT has been shown to influence the activity of a variety of ion channels in a number of molluscan species. These include the opening and closing of a number of 
different potassium channels as well as the increase in amplitude of voltage-gated calcium currents (Gerschenfeld and PaupardinTritsch, 1974; Deterre et al., 1982; Klein et al., 1982; PaupardinTritsch et al., 1986; Kirk et al., 1988; Levitan and Levitan, 1988; Taussig et al., 1989; Blumenfeld et al., 1990). 5-HT has also been shown to activate or enhance sodium currents in a number of molluscan preparations. Early studies by Gerschenfeld and Paupardin-Tritsch (1974) revcaled the presence of two kinetically distinct 5-HT-activated sodium currents in nonidentified neurons from both Aplysia and Helix. Furthermore, in Aplysia, 5-HT-activated sodium currents have been localized in motoneurons B16 (Kirk et al., 1988) and B15 (Taussig et al., 1989).

In the present study, the functional aspects of the actions of 5-HT on Helisorna neuron B19 served as a starting point for determining in detail the mechanism by which this function is carried out. 5-HT depolarizes neuron B19 as a first step in a cascade of events leading to the cessation of neurite outgrowth (Kater and Mills, 1991). Here, we show that 5-HT activates a cAMP-dependent sodium current in cell bodies of B19 that produces a robust, sustained depolarization under current-clamp conditions. This strongly suggests that this signal transduction pathway initiates 5-HT's actions on growth cone motility and neurite outgrowth in B19. However, absolute confirmation of this hypothesis is difficult since the 5-HT-activated current is carried by sodium ions. Elimination of sodium would prevent both the 5-HT-induced depolarization and action potential generation, which are known to be essential components of the neurite outgrowth response (McCobb and Kater, 1988). Demonstration that the signal transduction pathway described herein is also present in the growth cones of neuron B19 would further support its role in the neurite outgrowth response.

Studies of Helisoma embryos indicate that the action of 5-HT on adult B19s may reflect the expression of mechanisms that are utilized during nervous system development. In vivo experiments showed that 5-HT depletion during embryogenesis produces aberrations in B19 morphology and synaptogenesis (Goldberg and Kater, 1989). Furthermore, 5-HT can influence the outgrowth state of a large population of cultured embryonic Hclisoma neurons (Goldberg et al., 1991). Taken together, these studies suggest the receptor-ion channel tandem examined herein may play an important role during nervous system development. Electrophysiological study of cultured embryonic $\mathrm{Hel}$ isoma neurons has shown these neurons to be electrically excitable, possessing a full array of voltage-gated ion currents soon after they differentiate (Goldberg and Price, 1991). Given that large numbers of embryonic neurons respond to 5-HT with changes in neurite outgrowth (Goldberg et al., 1991) and intracellular calcium concentration (Goldberg et al., 1992b), it will be interesting to see if the mechanism of 5-HT-induced depolarization described in this study of an adult neuron is expressed in embryonic neurons.

\section{Cyclic nucleotide dependence of 5-HT-activated sodium current}

From our results examining the possibility of a second messenger mediating the activation of 5-HT-dependent sodium current, three lines of evidence suggest that cAMP serves such a role. First, the three treatments used in this study to increase intracellular levels of cAMP, membrane permeable analogs of cAMP, the adenylate cyclase stimulator forskolin, and the phosphodiesterase inhibitor IBMX, were all effective in eliciting in- ward current. Second, since the amplitude of IBMX-induced current was greater in 5-HT-stimulated cells than in nonstimulated cells, the B19 5-HT receptor appears to be coupled to a cyclase and can stimulate cyclic nucleotide formation. Finally, preloading neurons with cAMP analogs was effective at preventing 5-H'l's ability to cause inward current activation. Interestingly, single-channel studies have identified an ion channel in B 19 whose activity can be stimulated in ccll-attached patches following bath application of $25 \mu \mathrm{M} 5-\mathrm{HT}$, or in the absence of 5-HT by exposure of the neuron to IBMX or 8-bromo-cAMP (Price and Goldberg, 1992). Based on its ability to carry sodium ions and its apparent cAMP dependency, it is likely that this ion channel is responsible for 5-HT-dependent depolarization of B19.

In order to determine if activation of the sodium current involved a phosphorylation-dependent step, the ability of protein kinase inhibitors to inhibit current activation was tested. The ineffectiveness of $\mathrm{H} 7$ and $\mathrm{H} 89$ to prevent current activation and depolarization, while not proving that protein kinase activity is not involved in current gating, strongly suggests that cAMP directly gates the ion channel. Supporting this hypothesis is the recent finding that $\mathrm{H} 7$ is an effective inhibitor of a different response in Helisoma B19 that does involve cAMP-dependent kinase activity (Funte and Haydon, 1992). Moreover, sodium conductances gated directly by cAMP have been observed previously in molluscan neurons, occurring in anterior and medial neurons from the pleural ganglion of Aplysia, as well as in neurons from Pleurobranchia (Green and Gillette, 1983; Kehoe, 1990).

An additional indirect source of evidence that the channel carrying 5-HT-dependent sodium current is directly activated by cyclic nucleotides arises from the results of the low-calcium/ IBMX experiments. Since IBMX potentiated current was much larger under low-calcium conditions than under normal-calcium conditions, it is likely that calcium partially inhibits this current. However, under sodium-free conditions calcium appears to also permeate the channel. Similar characteristics have also been observed with the cyclic nucleotide-gated channels found in vertebrate rods and olfactory receptors. It has been proposed that calcium ions permeate these channels, but have longer residency times within the pore giving smaller currents than seen under low calcium conditions (Zimmerman and Baylor, 1986 1992; Kurahashi, 1989; Dhallan et al., 1990; Kaupp, 1991). Further experiments examining the ability of cAMP to stimulate channel activity in cell-free patches from neuron B19 are underway to test this hypothesis further.

\section{Pharmacological characterization of the B19 5-HT receptor}

Although several different responses to 5-HT have been characterized in mollusks, little is known about the pharmacology of 5-HT receptors mediating these responses. Therefore, we undertook an examination of the pharmacological nature of the B19 5-HT receptor to compare this receptor to other molluscan and vertebrate 5-HT receptors. Results from dose-response experiments suggest the B19 5-HT receptor has a relatively high affinity for 5-HT. Dose-response data has also been reported for two actions of 5-HT in Helisoma embryos. The $\mathrm{ED}_{50}$ for both the modulation of neurite outgrowth in embryonic neurons (Goldberg et al., 1991) and the stimulation of ciliary activity in intact embryos (Diefenbach et al., 1991) is approximately 100fold higher than what we report here. While poor access to receptor sites may account for the lower affinity seen in the 
ciliary response, differences seen in the activities of indole agonists (Goldberg et al., 1992a) suggest that it is mediated by a different receptor type than that studied here. Recently, a 5-HT receptor has been cloned from the pond snail Lymnaea stagnalis and expressed in Cos-7 cells (Sugamori et al., 1993). Receptor binding experiments indicated a relatively low affinity for 5-HT, again suggesting that this Lymnaea receptor may be different than the B19 5-HT receptor. Functional analysis of the Lymnaea 5-HT receptor is required to allow for further comparison between these two receptor types.

The use of pharmacological drugs to characterize the B19 5-HT receptor was hampered by the finding that many of the classical agonists and antagonists used to describe vertebrate 5-HT receptors had nonspecific actions on Helisoma neurons (C. J. Price and J. I. Goldberg, unpublished observations). Cyproheptadine, mianserin, and 8-OH-DPAT all appeared to inhibit 5-HT-dependent activation of sodium current. However, all were very effective and reversible inhibitors of voltage-dependent sodium and potassium currents. Therefore, it cannot be determined from these results if these drugs are acting at the receptor or are acting as nonspecific ion channel blockers, since the electrophysiological assay of receptor pharmacology used in this study cannot differentiate between the two possibilities.

Useful results were obtained from analysis of the agonist activities of the indoles tryptamine, 5-CT, and $\alpha \mathrm{m}-5-\mathrm{HT}$. All of these compounds showed only weak activity at the B19 5-HT receptor, underscoring the structural specificity needed for full binding and/or activation of the receptor. Interestingly, a 5-HT receptor that has greater affinity for 5-HT than for most other putative agonists and antagonists, including 5-CT, has recently been cloned from rat brain (Teitler et al., 1992). Taken together with its relatively high affinity for 5-HT, its apparent coupling to the cAMP second messenger system, and its activation by 5-CT, the Helisoma B19 5-HT receptor shares properties common to the vertebrate $5-\mathrm{HT}$, family of receptors. Alternatively, positive coupling of the B19 5-HT receptor to adenylate cyclase and the limited effectiveness of the indole agonists suggest that this receptor may be more closely related to the $5-\mathrm{HT}_{4}$ receptor family (Dumuis et al., 1988; Bockaert et al., 1992). Only through binding studies and molecular cloning of the Helisoma B19 5-HT receptor can these relationships be resolved.

\section{References}

Blumenfeld H, Spira ME, Kandel ER, Siegelbaum SA (1990) Facilitatory and inhibitory transmitters modulate calcium influx during action potentials in Aplysia sensory neurons. Neuron 5:487-499.

Bockacrt J, Fozard JR, Dumuis A, Clarke DE (1992) The 5-HT 4 receptor: a place in the sun. Trends Neurosci 13:141-145.

Budnik V, Wu C-F, White K (1989) Altered branching of serotonincontaining neurons in Drosophila mutants unable to synthesize serotonin and dopamine. J Neurosci 9:2866-2877.

Cohan CS, Connor JA, Kater SB (1987) Electrically and chemically mediated increases in intracellular calcium in neuronal growth cones. J Neurosci 7:3588-3599.

Deterre P, Paupardin-Tritsch D, Bockaert J, Gerschenfeld HM (1982) cAMP-mediated decrease in $\mathrm{K}^{+}$conductance evoked by serotonin and dopamine in the same neuron: a biochemical and physiological single-cell study. Proc Natl Acad Sci USA 79:7934-7938.

Dhallan RS, Yau K-W, Schrader KA, Reed RR (1990) Primary structure and functional expression of a cyclic nucleotide-activated channel from olfactory neurons. Nature 347:184-187.

Diefenbach TJ, Koehncke NK, Goldberg JI (1991) Characterization and development of rotational behavior in Helisoma embryos: role of endogenous serotonin. J Neurobiol 22:922-934.

Dumuis A, Bouhelal R, Sebben M, Cory R, Bockaert J (1988) A nonclassical 5-hydroxytryptamine receptor positively coupled with adenylate cyclase in the central nervous system. Mol Pharmacol 34: 880-887.

Funte LR, Haydon PG (1992) H-7 prevents target induced enhancement of action potential evoked calcium accumulation in the presynaptic neuron during synaptogenesis. Soc Neurosci Abstr 18:23.11.

Gerschenfeld HM, Paupardin-Tritsch D (1974) Ionic mechanisms and receptor properties underlying the responses of molluscan neurones to 5-hydroxytryptamine. J Physiol (Lond) 243:427-456.

Goldberg JI, Kater SB (1989) Expression and function of the neurotransmitter serotonin during development of the Helisoma nervous system. Dev Biol 131:483-495.

Goldberg JI, Price CJ (1991) Voltage-gated ionic currents in neurons isolated from Helisoma trivolvis embryos. In: Molluscan neurobiology (Kitts KS, Boer HH, Josse J, eds), pp 161-167. Amsterdam: North Holland.

Goldberg JI, Mills LR, Kater SB (1991) Novel effects of serotonin on neurite outgrowth in neurons cultured from embryos of Helisoma trivolvis. J Neurobiol 22:182-194.

Goldberg JI, Koehncke NK, Price CJ, Diefenbach TJ (1992a) Pharmacological characterization of serotonin receptors in the snail $\mathrm{Hel}$ isoma trivolvis. Can Soc Zool Bull 23:59.

Goldberg JI, Mills LR, Kater SB (1992b) Effects of serotonin on intracellular calcium in embryonic and adult Helisoma neurons. Int $\mathrm{J}$ Dev Neurosci 10:255-264.

Green DJ, Gillette R (1983) Patch and voltage clamp analysis of cAMP-stimulated inward current underlying neurone bursting. Nature 306:784-785.

Hamill OP, Marty A, Neher E, Sakmann B, Sigworth FJ (1981) Improved patch-clamp techniques for high-resolution current recordings from cells and cell-free membrane patches. Pfluegers Arch 391:85100.

Haydon PG, McCobb DP, Kater SB (1984) Serotonin selectively inhibits growth cone motility and synaptogenesis of specific identified neurons. Science 226:561-564.

Haydon PG, Cohan CS, Miller HR, McCobb DP, Kater SB (1985) Neuron specific growth cone properties as seen in identified neurons of Helisoma. J Neurosci Res 13:135-147.

Haydon PG, McCobb DP, Kater SB (1987) The regulation of neurite outgrowth, growth cone motility, and electrical synaptogenesis by serotonin. J Neurobiol 18:197-215.

Kater SB, Mills LR (1991) Regulation of growth cone behavior by calcium. J Neurosci 11:891-899.

Kaupp UB (1991) The cyclic nuclcotidc-gatcd channcls of vertcbrate photoreceptors and olfactory epithelium. Trends Neurosci 14:150 157.

Kehoe J (1990) Cyclic AMP-induced slow inward current in depolarized neurons of Aplysia californica. J Neurosci 10:3194-3207.

Kirk MD, Taussig R, Scheller RH (1988) Egg-laying hormone, serotonin, and cyclic nucleotide modulation of ionic currents in the identified motoneuron B16 of Aplysia. J Neurosci 8:1181-1193.

Klein M, Camardo J, Kandel ER (1982) Serotonin modulates a specific potassium current in the sensory neurons that show presynaptic facilitation in Aplysia. Proc Natl Acad Sci USA 79:5713-5717.

Kurahashi T (1989) Activation by odorants of cation-selective conductance in the olfactory receptor cell isolated from the newt. J Physiol (Lond) 419:177-192.

Lankford K, De Mello FG, Klein WL (1987) A transicnt cmbryonic dopamine receptor inhibits growth cone motility and neurite outgrowth in a subset of avian retina neurons. Neurosci Lett 75:169174.

Levitan ES, Levitan IB (1988) Serotonin acting via cyclic AMP enhances both the hyperpolarizing and depolarizing phases of bursting pacemaker activity in the Aplysia neuron R15. J Neurosci 8:11521161.

Mattson MP, Kater SB (1987) Calcium regulation of neurite elongation and growth cone motility. J Neurosci 7:4034-4043.

Mattson MP, Lee RE, Adams ME, Guthrie PB, Kater SB (1988a) Interactions between entorhinal axons and target hippocampal neurons: a role for glutamate in the development of hippocampal circuitry. Neuron 1:865-876.

Mattson MP, Taylor-Hunter A, Katcr SB (1988b) Ncuritc outgrowth in individual neurons of a neuronal population is differentially regulated by calcium and cyclic AMP. J Neurosci 8:1704-1711.

McCobb DP, Kater SB (1988) Membrane voltage and neurotransmitter regulation of neuronal growth cone motility. Dev Biol 130: 599-609. 
Paupardin-Tritsch D, Hammond C, Gerschenfeld HM (1986) Serotonin and cyclic GMP both induce an increase of the calcium current in the same identified molluscan neurons. J Neurosci 6:2715-2723.

Peroutka SJ (1988) 5-Hydroxytryptamine receptor subtypes. Annu Rev Neurosci 11:45-60.

Polak K, Edelman AM, Wasley JWF, Cohan CS (1991) A novel calmodulin antagonist, CGS 9343B, modulates calcium-dependent changes in neurite outgrowth and growth cone movements. J Neurosci 11:534-542.

Price CJ, Goldberg JI (1992) Single channel conductance underlying serotonin dependent depolarization of an identified neuron from $\mathrm{Hel}$ isoma. Soc Ncurosci Abstr 18:115.14.

Sikich L, Hickok JM, Todd RD (1990) 5-HT ${ }_{1 A}$ receptors control neurite branching during development. Dev Brain Res 56:269-274.

Sugamori KS, Sunahara RK, Guan H-C, Bulloch AGM, Tensen CP, Seeman P, Niznik HB, Van Tol HHM (1993) Serotonin receptor
cDNA cloned from Lymnaea stagnalis. Proc Natl Acad Sci USA 90: 11-15.

Taussig R, Sweet-Cordero A, Scheller RH (1989) Modulation of ionic currents in Aplysia motor neuron B15 by serotonin, neuropeptides, and second messengers. J Neurosci 9:3218-3229.

Teitler M, Miller KJ, Hoffman BJ (1992) Cloning and characterization of a novel 5-CT insensitive (5- $\mathrm{HT}_{\text {IE }}$ ) receptor. Soc Neurosci Abstr 18:198.5.

Wong RG, Hadley RD, Kater SB, Hauser GC (1981) Neurite outgrowth in molluscan organ and cell cultures: the role of conditioning factors. J Neurosci 1:1008-1021.

Zimmerman AL, Baylor DA (1986) Cyclic GMP-sensitive conductance of retinal rods consists of aqueous pores. Nature 321:70-72.

Zimmerman AL, Baylor DA (1992) Cation interactions within the cyclic GMP-activated channel of retinal rods from the tiger salamander. J Physiol (Lond) 449:759-783. 